\title{
Salinity-induced modulation of growth and antioxidant activity in the callus cultures of miswak (Salvadora persica)
}

\author{
Varsha Sharma $\cdot$ Kishan Gopal Ramawat
}

Received: 11 January 2012/ Accepted: 3 April 2012/Published online: 24 April 2012

(C) The Author(s) 2012. This article is published with open access at Springerlink.com

\begin{abstract}
Miswak (Salvadora persica Linn.) is a medium-sized tree, desert facultative halophytic plant. Besides edible fruits and non-edible seed oil, the plant contains several bioactive compounds like alkaloids, tannins, saponins and sterols related to food and cosmetic industries. In the present study, physiological responses and antioxidant potential under salinity stress were investigated in callus cultures of $S$. persica to evaluate its use as a source of antioxidant. The callus cultures were grown on MS medium supplemented with $0.5 \mathrm{mg} / \mathrm{l}$ each of 2,4,5-T and BAP, which could be established successfully by regular subcultures of slow growing callus on this medium for several months. Increased dry weight, soluble proteins, proline, soluble carbohydrates and CAT activity were recorded under $\mathrm{NaCl}$ stress in comparison to control cultures. The DPPH and FRAP antioxidant activities were gradually elevated in $\mathrm{NaCl}$-treated callus, whereas SOD quenching was recorded maximum at $200 \mathrm{mM}$. A significant correlation between antioxidant capacity and phenol content was observed, indicating that phenolic compounds are the major contributors to the antioxidant potential in S. persica. These findings suggest that increased salinity stress caused elevated antioxidant potentials and the plants grown in such conditions may serve as potential source of antioxidant.
\end{abstract}

Keywords Antioxidant - Catalase - Salinity · Salvadora persica $\cdot$ Phenolics $\cdot$ Proline

V. Sharma $\cdot$ K. G. Ramawat $(\bowtie)$

Department of Botany, Laboratory of Bio-Molecular

Technology, M. L. Sukhadia University,

Udaipur 313001, India

e-mail: kg_ramawat@yahoo.com

$\begin{array}{ll}\text { Abbreviations } \\ \text { BAP } & \text { 6-Benzyl aminopurine } \\ \text { ROS } & \text { Reactive oxygen species } \\ \text { SOD } & \text { Superoxide dismutase } \\ \text { CAT } & \text { Catalase } \\ 2,4,5-\mathrm{T} & 2,4,5 \text {-Trichlorophenoxy acetic acid } \\ \mathrm{H}_{2} \mathrm{O}_{2} & \text { Hydrogen peroxide } \\ \text { DPPH } & \text { 1,1-Diphenyl-2-picrylhydrazyl } \\ \text { FRAP } & \text { Ferric reducing antioxidant potential } \\ \text { TPC } & \text { Total phenolic content }\end{array}$

\section{Introduction}

High salinity, drought, extreme light and temperature are the most serious environmental stresses impending plant growth and limiting crop productivity worldwide (Munns 2005). In salt affected plants, the result is primarily an ionic imbalance and hyper osmotic stress (Tester and Davenport 2003). The effect of this imbalance or disruption in homeostasis occurs at the cell as well as the whole plant levels. Finally, in extreme saline condition, molecular damage and growth arrest lead to death of plant (Jitesh et al. 2006). Salt-tolerant plants have evolved a variety of physiological responses that confer capacity for osmotic adjustment. These plants accumulate osmolytes such as glycine, betaine and proline that maintain the osmotic balance disrupted by the presence of ions in the vacuole (Wang et al. 2004). Investigations of halophytes indicated that significantly increased levels of proline and soluble carbohydrates are probably related to osmotic adjustment and the protection of membrane stability under salinity stresses (Megdiche et al. 2007). Proteins that accumulate in plants under saline conditions may provide a storage form 
of nitrogen that is re-utilized later and also play a role in osmotic adjustment.

In accordance with the established mechanism of ROS generation, oxidative stress has been reported in several plant species after $\mathrm{NaCl}$ stress treatment. Further, plant materials containing phenolic compounds are increasingly of interest for the food industry as they participate in the defense against ROS. Thus, drought-stressed plants might represent potential sources of polyphenols for economical use (Bettaieb et al. 2011). The correlation between antioxidant capacity and salt tolerance was demonstrated in a large number of plants, including salt-tolerant glycophytes and true halophytes such as Beta maritime, Cassia angustifolia and Crithmum maritimum (Li 2008).

Salvadora persica Linn. (Family Salvadoraceae) is a typical facultative halophytic plant, grows in arid regions from western India to Middle East as well as high saline lands along the sea coasts. It is an important plant of arid horticulture (edible fruits and non-edible seed oil) and forestry, hence micropropagation method has been developed (Phulwaria et al. 2011). The WHO recommends and encourages the use of chewing sticks of miswak as an effective oral hygiene procedure in areas where its use is traditional WHO (1987). The plant shows several biological activities (antimicrobial, dental plaque and gingivitis, anti-inflammatory and analgesic) due to major bioactive compounds like alkaloids, tannins, saponins and sterols (Ahmad et al. 2011; Akhtar et al. 2011; Sofrata et al. $2011 \mathrm{a}, \mathrm{b})$. In harsh saline and hot desert conditions, these plants support wild life and are integral part of ecosystem. Details of biology, physiology and usage have been reviewed (Kasera and Mohammed 2010; Khan et al. 2006; Sen et al. 2002).

Cell and tissue culture offers monitoring plant responses to salinity at biochemical and physiological levels (Yang et al. 2010; Matkowaski 2008). In the present study, $S$. persica callus cultures have been used for the first time to investigate salt stress adaptive mechanism, and correlate with antioxidant activity under salt stress for its possible use as a source of antioxidant in salty desert conditions.

\section{Materials and methods}

Plant material and growth conditions

The explants were obtained from 20- to 30-year-old mature tree of $S$. persica growing near to the University campus. The explants were washed under running tap water for $20 \mathrm{~min}$ to remove any adherent particles. Thoroughly washed explants were then immersed in $1 \%$ (v/v) Teepol, a liquid detergent for 2-3 min, and thereafter surface sterilized in ethanol for $30 \mathrm{~s}$. The explants were immersed in $0.1 \%(\mathrm{w} / \mathrm{v})$ aqueous solution of $\mathrm{HgCl}_{2}$ for $10 \mathrm{~min}$, rinsed with distilled water and then suitable size nodal explants $(\sim 1 \mathrm{~cm})$ were inoculated on to the medium. $\mathrm{Mu}-$ rashige and Skoog (1962) (MS) medium contained $3 \%$ sucrose, $0.8 \%$ agar with different combinations and concentrations of plant growth regulators. The $\mathrm{pH}$ was adjusted to 5.8 and autoclaved at $121{ }^{\circ} \mathrm{C}$ for $20 \mathrm{~min}$. Organic supplements like coconut milk $(10 \%)$ and all vitamins (twofold) were used for the improvement of callus growth and friability. The callus was then separated from the initial explants and subcultured every 30-35 days. The callus was maintained on MS medium with combinations of 2,4,5-T and BAP, $0.5 \mathrm{mg} / \mathrm{l}$ each, $3 \%$ (w/v) sucrose, double vitamins and $0.8 \%(\mathrm{w} / \mathrm{v})$ agar.

For salt stress experiment, different $\mathrm{NaCl}$ concentrations $(0,50,100$ and $200 \mathrm{mM})$ were added in MS medium and $40 \mathrm{ml}$ medium was poured in 100-ml wide-mouth conical flasks. The callus $(2.0 \mathrm{~g})$ was inoculated in each flask and these cultures were incubated at $25 \pm 0.2{ }^{\circ} \mathrm{C}$ under a $16 \mathrm{~h} \mathrm{~d}^{-1}$ photoperiod with $50 \mu \mathrm{mol} \mathrm{m} \mathrm{m}^{-2} \mathrm{~s}^{-1}$ irradiance. Fresh weight (FW) and dry weight (DW) were determined after 30-day growth.

\section{Soluble protein analysis}

The samples were collected from untreated and 30-day $\mathrm{NaCl}$-treated callus for estimation of soluble proteins. The callus (250 mg) was ground in chilled tris-(hydroxymethyl) amino methane (Tris)-HCl buffer (10 mM, pH 6.8), then centrifuged at $15,000 \mathrm{~g}$ for $20 \mathrm{~min}$. The supernatants obtained were used for protein assay according to the method of Bradford (1976) using bovine serum albumin as a standard.

\section{Proline and soluble carbohydrate assay}

The amount of proline was estimated by the ninhydrin method using fresh callus $(0.5 \mathrm{~g})$ in $3 \%$ sulfosalicylic acid and organic phase monitored at $520 \mathrm{~nm}$ by spectrophotometer (Specord 200, Analyte Jena, Germany) (Bates et al. 1973). A modification of the method of phenol-sulfuric acid was used to determine soluble sugar content at $490 \mathrm{~nm}$ (Dubois et al. 1956).

Catalase activity measurement

Catalase activity was measured by the method of Aebi (1974). The assay system comprised $50 \mathrm{mM}$ phosphate buffer ( $\mathrm{pH} 7.0$ ), $20 \mathrm{mM} \mathrm{H} \mathrm{O}_{2}$, and a suitable aliquot of enzyme in the final volume of $3 \mathrm{ml}$. The change of absorption values was recorded at $240 \mathrm{~nm}$ for $3 \mathrm{~min}$. CAT activity was estimated by calculating the initial rate of disappearance of $\mathrm{H}_{2} \mathrm{O}_{2}$. 
Determination of antioxidant activity

Antioxidant activity was determined by extraction of samples, which were pooled and analyzed in triplicates. Dried powdered callus sample (200 mg) was extracted $12 \mathrm{~h}$ at room temperature by shaking on a test tube rotator with $5 \mathrm{ml}$ of $70 \%$ methanol. The samples were centrifuged at $10,000 \mathrm{~g}$ for $10 \mathrm{~min}$ at $10{ }^{\circ} \mathrm{C}$ and supernatant was used for antioxidant activities.

\section{DPPH radical scavenging activity}

The 1,1-diphenyl-2-picrylhydrazyl (DPPH) radical scavenging activity was determined according to the method described by Hatano et al. (1988). The reaction mixture (total volume $3 \mathrm{ml}$ ), consisting of $0.5 \mathrm{ml}$ of $0.5 \mathrm{M}$ acetic acid buffer solution at $\mathrm{pH} 5.5,1 \mathrm{ml}$ of $0.2 \mathrm{mM}$ DPPH in ethanol, and $1.5 \mathrm{ml}$ of $50 \%(\mathrm{v} / \mathrm{v})$ ethanol aqueous solution, was shaken vigorously with various samples. After incubation at room temperature for $30 \mathrm{~min}$, the remaining DPPH was determined by absorbance at $517 \mathrm{~nm}$, and the radical scavenging activity of each sample was expressed using the ratio of the absorption decrease of DPPH (\%) to that of the control DPPH solution $(100 \%)$ in the absence of the sample. The radical scavenging activity was calculated as $(\%)=100(A-B) / A$, where $A$ and $B$ are the $517 \mathrm{~nm}$ absorption of the control and the corrected absorption of the sample reaction mixture.

Superoxide radical scavenging activity

(PMS/NADH system)

Superoxide anions were generated using PMS/NADH system. The superoxide anions are subsequently made to reduce nitroblue tetrazolium (NBT) which yields a chromogenic product, which is measured at $560 \mathrm{~nm}$. The absorbance was read at $560 \mathrm{~nm}$ (Jain et al. 2008) and the inhibition percentage of superoxide anion generation was calculated the same as DPPH activity formula.

Ferric reducing antioxidant potential (FRAP) assay

The ferric reducing power of plant extracts was determined using the method of Benzie and Strain (1996). The reaction mixture, containing $100 \mu \mathrm{l}$ of sample solutions, $300 \mu \mathrm{L}$ of deionized water and $3 \mathrm{ml}$ of FRAP reagent, was incubated for $30 \mathrm{~min}$ at $37{ }^{\circ} \mathrm{C}$ in a water bath and read at $593 \mathrm{~nm}$. The difference between sample absorbance and blank absorbance was calculated and used to calculate the FRAP value. FRAP values were expressed as mmol $\mathrm{Fe}^{2+} / \mathrm{g}$ of sample.
Determination of total phenolic content

Phenolic compounds were assayed using the Foline-Ciocalteu reagent, by following the method of Farkas and Kiraly (1962). TPC was expressed as mg gallic acid equivalents (GAE) $\mathrm{g}^{-1} \mathrm{DW}$ through the calibration curve with gallic acid at $650 \mathrm{~nm}$.

Statistical analysis

All results were averaged over three separate analyses from six flasks of each treatment and experiment was done in duplicate. Results were reported as the mean \pm standard deviation (SD) and analyzed by ANOVA followed by post hoc least significant difference (LSD) test at $P \leq 0.05$ using prism statistical software. To correlate the results obtained with different methods, a regression analysis was performed and correlation coefficients were calculated.

\section{Results and discussion}

The results obtained with callus tissues of $S$. persica grown under $\mathrm{NaCl}$-generated salinity stress showed increased salt tolerance in cells as evident by higher dry weight, metabolic and antioxidant activities. Being a slow growing desert plant, initial growth of the callus produced from mature explants was very slow on different permutations and combinations of MS medium salts, plant growth regulators and complex addendum. However, soft, friable and cream colored cultures could be established after several subcultures on the medium containing a combination of 2,4,5-T and BAP (0.5 mg/l each), $3 \%$ (w/v) sucrose, double vitamins and $0.8 \%(\mathrm{w} / \mathrm{v})$ agar. On this medium, metabolically active cells were visible under microscope (Fig. 1a, b). Salt stress creates both ionic as well as osmotic stress on plants.

Effect of $\mathrm{NaCl}$ on growth and soluble protein contents

Reduced fresh weight with higher or same dry weight and protein contents were observed in the callus after 30-day growth on the medium with $\mathrm{NaCl}$ (Table 1). Loss of water with high salt concentration but increased dry matter and soluble protein showed high metabolic activity.

Fresh weight and dry weight are often measured to reveal the growth of plants and cells in response to environmental stresses. In the present study, salt concentrations induced significant elevation in dry weight in S. persica callus, which suggest a cellular tolerance to lower salinity in this halophytic species. Similar results of growth were found in Nitraria tangutorum and Oryza sativa callus 

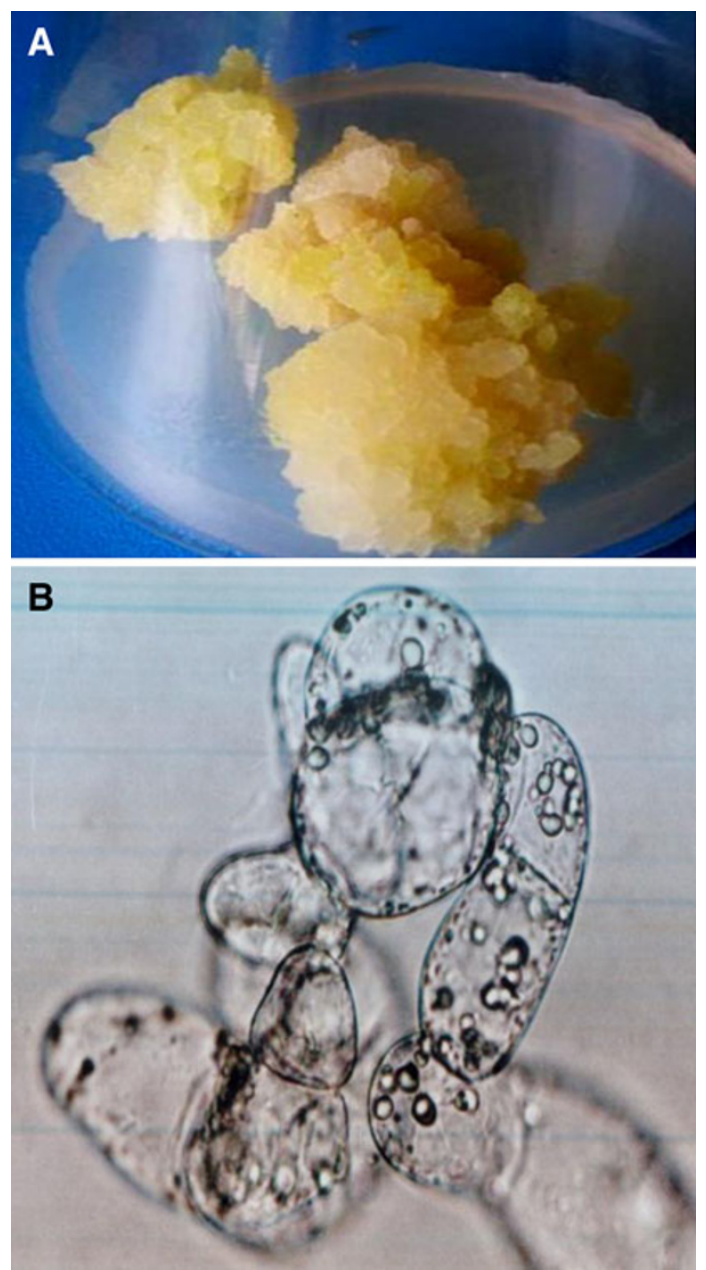

Fig. 1 a Callus and $\mathbf{b}$ cells of Salvadora persica

(Yang et al. 2010). The expression of proteins is regulated in plants depending on salt concentration (Sekmen et al. 2007; Yang et al. 2010). Proteins that accumulate in plants under saline conditions are cytoplasmic, which can cause alterations in cytoplasmic viscosity of the cells and may play a significant role in osmotic adjustment (Hasegawa et al. 2000). Similar results were also obtained in mulberry cultivars where soluble protein increased at low salinity and decreased at high salinity (Agastian et al. 2000).
Effect of $\mathrm{NaCl}$ stress on proline and soluble sugar contents

Proline level in response to $\mathrm{NaCl}$ treatment (Fig. 2) showed an approximately 1.30- and 2.09-fold increase in the content in the callus exposed to 50 and $100 \mathrm{mM} \mathrm{NaCl}$, respectively $(P<0.05)$, as compared with control cultures. However, treatment with $200 \mathrm{mM} \mathrm{NaCl}$ led to a decrease in proline content which was equivalent to that of control value. In callus cultures of $S$. persica, soluble sugar content increased significantly from 1.0- to 1.6-fold under salinity stress $(P<0.05$; Fig. 3). Therefore, it appears that proline possibly plays a more important role as an osmoprotectant in $S$. persica callus subjected to salinity stress than to soluble sugar.

Proline is known to play an important role as an osmoprotectant and is accumulated when plants are subjected to hyperosmotic stresses (Suriyan and Chalermpol 2009). Maintaining osmotic homeostasis by accumulating metabolically compatible compounds such as carbohydrates and proline may be among the important adaptive mechanisms of salinity tolerance in plants (Rosa et al. 2009). Increased proline and sugar contents were correlative with increased salinity stress in the callus of $S$. persica. In Sesuvium portulacastrum, treatment with $100 \mathrm{mM} \mathrm{NaCl}$ induced significantly increased levels of proline in the leaves, but it had no effect on soluble sugar content (Slama et al. 2007). Proline is also considered to be involved in the protection of enzymes, cellular structures, and to act as a free radical scavenger (Aghaleh et al. 2011).

\section{Effect of $\mathrm{NaCl}$ on CAT activity}

An increase in 82, 122 and $113 \%$ CAT activity was measured in the callus grown on 50, 100 and $200 \mathrm{mM}$ $\mathrm{NaCl}$ containing medium for 30 days, respectively, $(P<0.05)$, as compared to control culture values (Fig. 4).

An effective ROS-scavenging system involving catalase is a critical component of salinity resistance because of its protective effect against oxidative damage under salinity stress. Catalase is one of the main $\mathrm{H}_{2} \mathrm{O}_{2}$ scavenging enzymes that dismutate $\mathrm{H}_{2} \mathrm{O}_{2}$ into water and $\mathrm{O}_{2}$ (Moradi

Table 1 Effect of $\mathrm{NaCl}$ on the growth and soluble proteins of callus culture of Salvadora persica

\begin{tabular}{|c|c|c|c|c|}
\hline \multirow[t]{2}{*}{ Growth } & \multicolumn{4}{|c|}{$\mathrm{NaCl}$ concentrations $(\mathrm{mM})^{* \#}$} \\
\hline & Control & 50 & 100 & 200 \\
\hline Relative fresh weight (\%) & $100 \pm 1.20^{\mathrm{a}}$ & $91.66 \pm 1.05^{\mathrm{b}}$ & $83.33 \pm 1.15^{\mathrm{c}}$ & $66.66 \pm 1.54^{\mathrm{d}}$ \\
\hline Dry weight (mg) & $510 \pm 18.0^{\mathrm{bc}}$ & $580 \pm 15.5^{\mathrm{a}}$ & $540 \pm 20.3^{b}$ & $500 \pm 12.6^{\mathrm{c}}$ \\
\hline Soluble protein $\left(\mathrm{mg} \mathrm{g}^{-1} \mathrm{FW}\right)$ & $1.0 \pm 0.06^{\mathrm{c}}$ & $1.9 \pm 0.10^{\mathrm{a}}$ & $1.8 \pm 0.07^{\mathrm{a}}$ & $1.6 \pm 0.13^{\mathrm{b}}$ \\
\hline
\end{tabular}

* Values represented mean $\pm \mathrm{SD}$ calculated from at least three replicates of each treatment

\# Mean with common letter is not significantly different at $P \leq 0.05$, according to least significant difference (LSD) test 


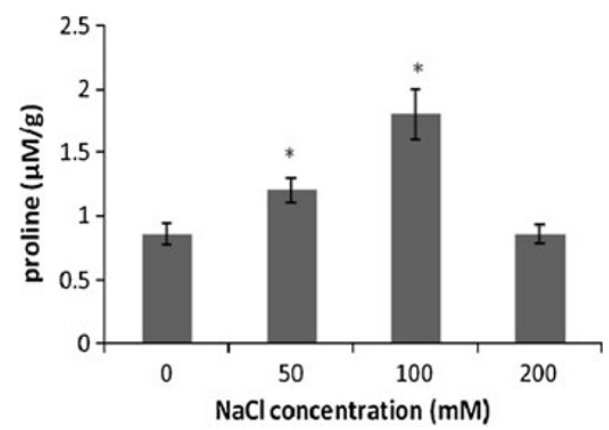

Fig. 2 The change of proline contents induced by $\mathrm{NaCl}$ treatment in the callus of $S$. persica. Data represent the mean $\pm \operatorname{SE}(n=3)$. *Significant differences between the control and treated callus $(P<0.05)$

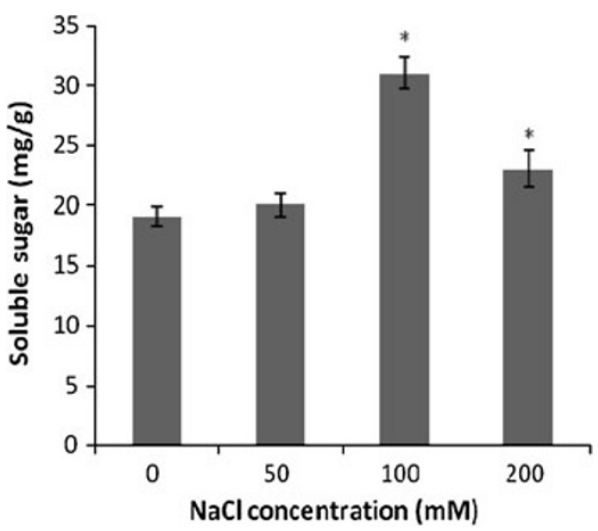

Fig. 3 The change of soluble sugar contents induced by $\mathrm{NaCl}$ treatment in the callus of Salvadora persica. Data represent the means \pm SE of at least three independent measurements. *Significant differences between the control and treated callus $(P<0.05)$

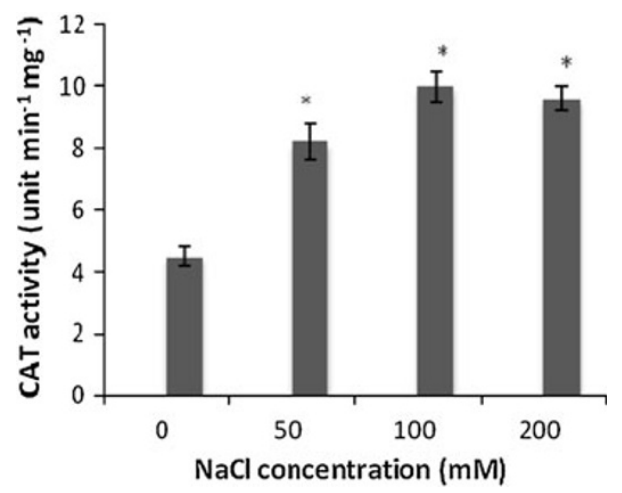

Fig. 4 The changes in CAT activity in $S$. persica callus treated with different $\mathrm{NaCl}$ concentrations. Data represent the mean $\pm \mathrm{SE}(n=3)$. *Significant differences between the control and $\mathrm{NaCl}$ treated callus $(P<0.05)$

and Ismail 2007; Li 2008). When Bruguiera parviflora plants were subjected to $400 \mathrm{mM} \mathrm{NaCl}$ stress condition, a decrease in total catalase activity was observed by Jitesh et al. (2006), while increased CAT activity was demonstrated in Nitraria tangutorum callus culture after 50 or $100 \mathrm{mM} \mathrm{NaCl}$ treatment (Yang et al. 2010). Thus, catalase enzyme activity varied with different plant species and with salt stress.

Effect of $\mathrm{NaCl}$ stress on antioxidant potential and total phenolic content

Antioxidant capacity was evaluated by DPPH and SOD anion activities. DPPH radical scavenging activity of callus cultures of $S$. persica increased gradually from 1.26- to 1.78 -fold when grown on increasing concentrations of $\mathrm{NaCl}$ for 30 days (Table 2). FRAP and SOD activities of $S$. persica callus cultures were also increased steadily from 9 to $12 \%$ and 11 to $17 \mathrm{mM} \mathrm{Fe}^{2+} \mathrm{g}^{-1}$ under 50 to $200 \mathrm{mM}$ $\mathrm{NaCl}$ treatments, respectively (Table 2). Increased protein and metabolites were correlative to increased TPC, DPPH, SOD and FRAP in the cells grown with increased salt stress as compared to control. The plant cells showed increase in all parameters under increased stress indicating a saltinduced response for survival in harsh temperature and salt conditions with increase of dry matter accumulation. Simultaneously, TPC of the callus cultures under salinity stress increased from 11 to $12 \mathrm{mg} \mathrm{GAE} \mathrm{g}^{-1}$ in the cultures grown on the medium with increased concentration of $\mathrm{NaCl}$ as compared to control cultures (Table 2).

\section{Correlation between assays}

In order to correlate the results obtained with the different methods, a regression analysis was performed (correlation coefficient $R$, Table 3). Significant correlations were established between FRAP and TPC ( $R=0.973$, Fig. 5), and SOD and TPC ( $R=0.852$, Fig. 6$)$ assay. A significant correlation ( $R=0.760$, Fig. 7) was also observed between FRAP and SOD assay. However, the negative correlations were found between FRAP and DPPH $(R=-0.164)$, SOD and DPPH $(R=-0.532)$ and TPC and DPPH $(R=-0.153)$ assays. The negative correlation coefficient of above assays shows that as the value of one variable increases, the value of other variable decreases, and vice versa. The DPPH activity commonly showed negative correlation with FRAP, SOD and TPC.

Salt-induced growth variations were correlated with parallel variations in polyphenols accumulation and antioxidative ability. NaCl-treated callus of $S$. persica demonstrated that DPPH radical scavenging activity, FRAP activity and SOD activity increased significantly. Similarly, Lechno et al. (1997) reported that $\mathrm{NaCl}$ treatment increases the activities of the antioxidative enzymes. These activities may be directly linked to the content of phenols, tannins and flavonoids and consequently to their free radical scavenging activities. Besides, plant resistance to 
Table 2 Effect of $\mathrm{NaCl}$ on the total phenolic content (TPC) and radical scavenging capacity of callus culture of Salvadora persica

\begin{tabular}{lcccc}
\hline TPC and antioxidant activity & \multicolumn{2}{l}{$\mathrm{NaCl}$ concentrations $(\mathrm{mM}) * \#$} & 100 & 200 \\
\cline { 2 - 5 } & Control & 50 & $11 \pm 0.34^{\mathrm{a}}$ & $12 \pm 0.86^{\mathrm{a}}$ \\
\hline TPC $\left(\mathrm{mg} \mathrm{GAE} \mathrm{g}^{-1}\right)$ & $10 \pm 0.45^{\mathrm{b}}$ & $11 \pm 0.70^{\mathrm{a}}$ & $58 \pm 3.4^{\mathrm{b}}$ & $82 \pm 4.1^{\mathrm{a}}$ \\
DPPH scavenging activity (\%) & $46 \pm 2.3^{\mathrm{d}}$ & $9 \pm 0.45^{\mathrm{b}}$ & $10 \pm 0.40^{\mathrm{b}}$ & $13 \pm 0.92^{\mathrm{a}}$ \\
SOD quenching (\%) & $6 \pm 0.37^{\mathrm{c}}$ & $11 \pm 0.40^{\mathrm{c}}$ & $13 \pm 0.55^{\mathrm{b}}$ & $17 \pm 1.03^{\mathrm{a}}$ \\
FRAP activity (mM Fe & $8 \pm 0.66^{\mathrm{d}}$ & $\left.\mathrm{g}^{-1}\right)$ & &
\end{tabular}

* Values represented mean $\pm \mathrm{SD}$ calculated from at least three replicates of each treatment

\# Mean with common letter is not significantly different at $P \leq 0.05$, according to least significant difference (LSD) test

Table 3 Correlation coefficient $(R)$ between assays

\begin{tabular}{lrrr}
\hline & FRAP & SOD & DPPH \\
\hline SOD & 0.760 & & \\
DPPH & -0.164 & -0.532 & \\
TPC & 0.973 & 0.852 & -0.153 \\
\hline
\end{tabular}

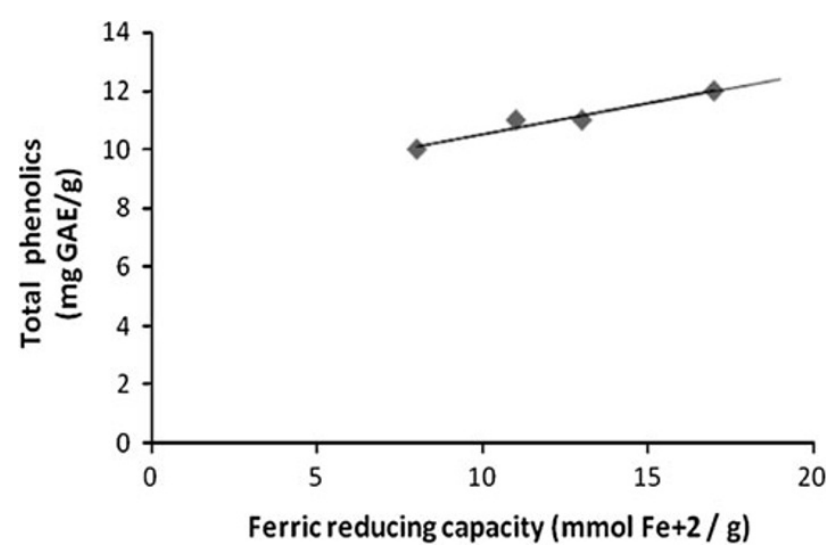

Fig. 5 Correlation between ferric reducing capacity (FRAP) and total phenolic content (TPC). Correlation coefficient $R=0.973$

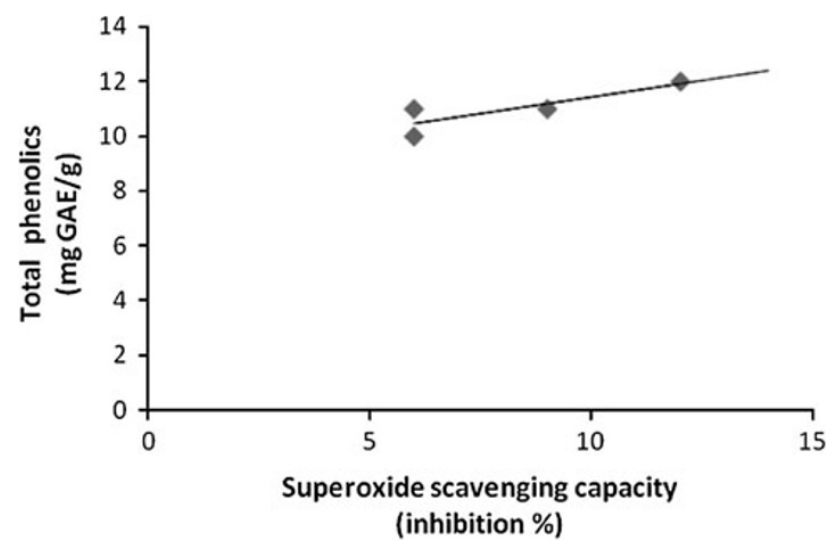

Fig. 6 Correlation between superoxide scavenging capacity (SOD) and total phenolic content (TPC). Correlation coefficient $R=0.852$

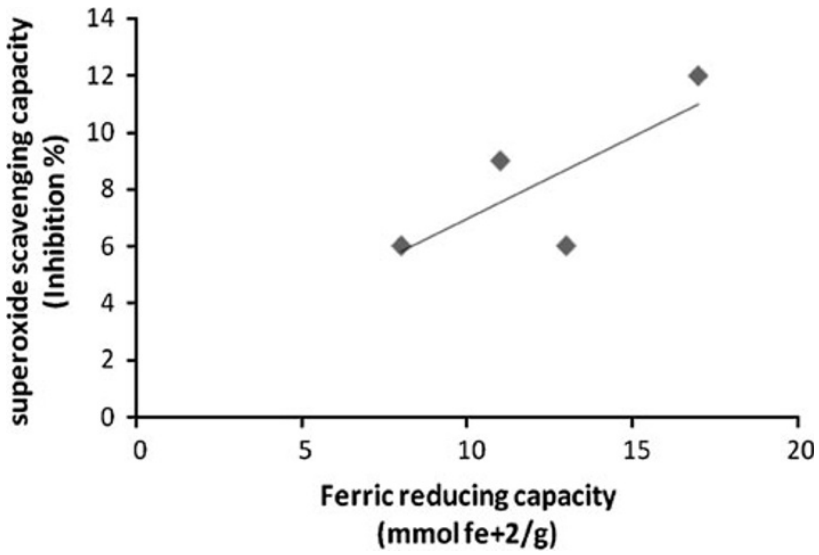

Fig. 7 Correlation between superoxide scavenging capacity (SOD) and ferric reducing capacity (FRAP). Correlation coefficient $R=0.760$

various stresses is associated with antioxidant capacity and increased levels of antioxidants may prevent stress damage (Bettaieb et al. 2011).

These results indicate a significant correlation between TPC in callus extract and their free radical scavenging and ferric reducing capacities (FRAP and SOD assays). Therefore, the presence of phenolic compounds in callus extracts contributed significantly to their antioxidant potential. In our experiments, results demonstrated a strong correlation between TPC and FRAP activity. Similarly, previous studies suggested that ferric reducing capacity can be related to phenolic content, indicating that phenolic compounds are the major contributor to the antioxidant potential of different plant extracts (Dudonne et al. 2009).

In conclusion, our results showed that salinity-induced in vitro cultures are better model system for the study of stress mechanism, which is independent from environmental factors. The callus cultures of $S$. persica showed moderate salt-tolerant properties and can be used as source of antioxidants in harsh saline desert conditions for humans (fruits) and cattle (leaves). 
Acknowledgments This work was supported by financial assistance from University Grants Commission-Departmental Research Programme (UGC-DRS) under special assistance program for medicinal plant research to K.G. Ramawat. V. Sharma thanks to UGC New Delhi, for financial assistance in the form of SRF.

Open Access This article is distributed under the terms of the Creative Commons Attribution License which permits any use, distribution, and reproduction in any medium, provided the original author(s) and the source are credited.

\section{References}

Aebi H (1974) Catalase. In: Bergmeyer HU (ed) In methods of enzymatic analysis. Academic Press, New York, pp 673-677

Agastian P, Kingsley SJ, Vivekanandan M (2000) Effect of salinity on photosynthesis and biochemical characteristics in mulberry genotypes. Photosynthetica 38:287-290

Aghaleh M, Niknam V, Ebrahimzadeh H, Razavi K (2011) Effect of salt stress on physiological and antioxidative responses in two species of Salicornia (S. persica and S. europaea). Acta Physiol Plant 33:1261-1270

Ahmad M, Imran H, Yaqeen Z, Rehman Z, Rahman A, Fatima N, Sohail T (2011) Pharmacological profile of Salvadora persica. Pak J Pharm Sci 24:323-330

Akhtar J, Siddique KM, Bi S, Mujeeb M (2011) A review on phytochemical and pharmacological investigations of miswak (Salvadora persica Linn). J Pharm Bioallied Sci 3:113-117

Bates CJ, Waldren RP, Teare ID (1973) Rapid determination of free proline for water-stress studies. Plant Soil 39:205-207

Benzie IFF, Strain JJ (1996) The ferric reducing ability of plasma (FRAP) as a measure of "antioxidant power": the FRAP assay. Anal Biochem 239:70-76

Bettaieb I, Sellami IH, Bourgou S, Limam F, Marzouk B (2011) Drought effects on polyphenol composition and antioxidant activities in aerial parts of Salvia officinalis L. Acta Physiol Plant 33:1103-1111

Bradford MM (1976) A rapid and sensitive method for the quantitation of microgram quantities of protein utilizing the principle of protein-dye binding. Anal Biochem 72:248-254

Dubois M, Gilles KA, Hamilton JK, Rebers PA, Smith F (1956) Colorimetric method for determination of sugars and related substances. Anal Chem 38:350-356

Dudonne S, Vitrac X, Coutiere P, Woillez M, Merillon JM (2009) Comparative study of antioxidant properties and total phenolic content of 30 plant extracts of industrial interest using DPPH, ABTS, FRAP, SOD, and ORAC assays. J Agric Food Chem 57:1768-1774

Farkas GL, Kiraly Z (1962) Role of phenolic compound in the physiology of plant diseases and disease resistance. Phytopathologische Zeitschrift 44:105-150

Hasegawa PM, Bressan RA, Zhu JK, Bohnert HJ (2000) Plant cellular and molecular responses to high salinity. Annu Rev Plant Physiol Plant Mol Biol 51:463-499

Hatano T, Kagawa H, Yasuhara T, Okuda T (1988) Two new flavonoids and other constituents in licorice root: their relative astringency and radical scavenging effects. Chem Pharm Bull 36:2090-2097

Jain PK, Ravichandran V, Agrawal RK (2008) Antioxidant and free radical scavenging properties of traditionally used three Indian medicinal plants. Curr Trends Biotech Pharm 2:538-547

Jitesh MN, Prashanth SR, Sivaprakash KR, Parida AK (2006) Antioxidative response mechanism in halophytes: their role in stress defence. J Genet 85:237-253
Kasera PK, Mohammed S (2010) Ecology of saline plants. In: Ramawat KG (ed) Desert plants biology and biotechnology. Springer, Heidelberg, pp 299-320

Khan MA, Ansari R, Gul B, Qadir M (2006) Crop diversification through halophyte production on salt prone land resources. $\mathrm{CAB}$ Rev Perspectives Agric Vet Sci Nutr Nat Resour 1:048. doi: 10.1079/PAVSNNR20061048

Lechno S, Zamski E, Telor E (1997) Salt stress-induced responses in cucumber plants. J Plant Physiol 150:206-211

Li Y (2008) Kinetics of the antioxidant response to salinity in the halophyte Limonium bicolor. Plant Soil Environ 54:493-497

Matkowaski A (2008) Plant in vitro culture for the production of antioxidants-a review. Biotech Adv 26:548-560

Megdiche W, Amor NDA, Hessini K, Ksouri R, Zuily-Fodil Y, Abdelly C (2007) Salt tolerance of the annual halophyte Cakile maritima as affected by the provenance and the developmental stage. Acta Physiol Plant 29:375-384

Moradi F, Ismail AM (2007) Responses of photosynthesis, chlorophyll fluorescence and ROS-scavenging systems to salt stress during seedling and reproductive stages in rice. Ann Bot 99:1161-1173

Munns R (2005) Genes and salt tolerance bringing them together. New Phytol 167:645-663

Murashige T, Skoog F (1962) A revised medium for rapid growth and bioassays with tobacco tissue cultures. Physiol Plant 15:473-497

Phulwaria M, Ram K, Gahlot P, Shekhawat NS (2011) Micropropagation of Salvadora persica - a tree of arid horticulture and forestry. New Forest. doi:10.1007/s11056-011-9254-z

Rosa M, Hilal M, González JA, Prado FE et al (2009) Lowtemperature effect on enzyme activities involved in sucrosestarch partitioning in salt-stressed and salt-acclimated cotyledons of quinoa (Chenopodium quinoa Willd.) seedlings. Plant Physiol Biochem 47:300-307

Sekmen AH, Turkan I, Takio S (2007) Differential responses of antioxidative enzymes and lipid peroxidation to salt stress in salt-tolerant Plantago maritima and salt-sensitive Plantago media. Physiol Plant 131:399-411

Sen DN, Mohammed S, Kasera PK (2002) Biology and physiology of saline plants. In: Pessarakli M (ed) Handbook of plant and crop physiology, 2nd edn. Dekker, New York, pp 563-581

Slama I, Ghnaya T, Messedi D, Hessini K, Labidi N, Savoure A, Abdelly C (2007) Effect of sodium chloride on the response of the halophyte species Sesuvium portulacastrum grown in mannitol-induced water stress. J Plant Res 120:291-299

Sofrata A, Brito F, Al-Otaibi M, Gustafsson A (2011a) Short term clinical effect of active and inactive Salvadora persica miswak on dental plaque and gingivitis. J Ethanopharmacol. doi: 10.1016/J-Jep2011.07.034

Sofrata A, Santangelo EM, Azeem M, Borg-Karlson AK, Gustafsson A, Pütsep K (2011b) Benzyl isothiocyanate, a major component from the roots of Salvadora persica is highly active against gram-negative bacteria. PLoS One 6:e23045

Suriyan C, Chalermpol K (2009) Proline accumulation, photosynthetic abilities and growth characters of sugarcane (Saccharum officinarum L.) plantlets in response to iso-osmotic salt and water-deficit stress. Agric Sci China 8:51-58

Tester M, Davenport R (2003) $\mathrm{Na}^{+}$tolerance and $\mathrm{Na}^{+}$transport in higher plants. Ann Bot 91:503-527

Wang B, Luttge U, Ratajczak R (2004) Specific regulation of SOD isoforms by $\mathrm{NaCl}$ and osmotic stress in leaves of the $\mathrm{C}_{3}$ halophytes Suaeda salsa L. J Plant Physiol 161:285-293

World Health Organization (1987) Prevention of oral diseases. WHO, Geneva

Yang Y, Wei X, Shi R, Fan Q, An L (2010) Salinity-induced physiological modification in the callus from halophytes Nitraria tangutorum Bobr. J Plant Growth Regul 29:465-476 